\title{
Prevention of cervical cancer: early detection of precancerous lesions of cervix in women from a marginalized environment
}

\author{
D. M. Christe ${ }^{1,2 *}$, Anjalakshi Chandrasekar ${ }^{3}$, K. Jayashree ${ }^{2}$, \\ P. Meenalochani ${ }^{2}$, Shaanthy T. K. Gunasingh ${ }^{2}$
}

\begin{abstract}
${ }^{1}$ National Institute for Research in Human Reproduction-Field Unit, Indian Council of Medical Research
${ }^{2}$ Institute of Obstetrics and Gynaecology, Madras Medical College, Chennai, India

${ }^{3}$ Department of Research, The Tamilnadu Dr. MGR Medical University, Chennai, India
\end{abstract}

Received: 01 October 2018

Accepted: 27 October 2018

*Correspondence:

Dr. D. M. Christe,

E-mail: drdmchriste@gmail.com

Copyright: () the author(s), publisher and licensee Medip Academy. This is an open-access article distributed under the terms of the Creative Commons Attribution Non-Commercial License, which permits unrestricted non-commercial use, distribution, and reproduction in any medium, provided the original work is properly cited.

\begin{abstract}
Background: The objective of the present study was to find out the efficacy of low-cost methods, available for screening for cervical cancer and early detection of precancerous lesions, of cervix.

Methods: The study with power above $80 \%$, was conducted over a period of almost three years. Women aged below fifty years were included in the study. A total of 100 women were diagnosed with cervical intraepithelial neoplasia (CIN) and 244 women with chronic cervicitis by histopathological examination reports. Ten women were HIV positive.

Results: Low cost screening tests of visual inspection of cervix after application of 5\% acetic acid (VIA) and visual inspection of cervix after application of Lugol's iodine (VILI) were positive in $75 \%$ of women with CIN and in combination with colposcopy, positive in $93 \%$. The diagnostic accuracy of colposcopy was highest at $86 \%$. (Odds ratio-.48.79).

Conclusions: Initial screening for younger women with fewer years of exposure, the low cost tests, VIA / VILI could be used under low magnification. Colposcopy should be done for all women with positive tests. The costlier human papilloma virus (HPV) tests should be done at cost effective purpose for high risk groups and when indicated, for early detection of precancerous lesions of cervix and prevention of cervical cancer.
\end{abstract}

Keywords: Colposcopy, Detection, Precancerous lesions cervix, Screening

\section{INTRODUCTION}

Nearly 3,12,752 new incidences of cervical cancer cases, which is above $50 \%$ of the worldwide total, occur in Asia. ${ }^{1,2}$ The disease is also more prevalent in women from lower socioeconomic group and rural areas. The main reason for this problem is the lack of awareness, difficulties faced by women from these groups in having access to treatment and inability to afford the costs required for screening and early treatment. ${ }^{3,4,5}$ The National Cancer Registry Programme (NCRP) showed Cancer of cervix is the most common genital cancer in women in India. The top three cancers in women in India, are cancers that can be prevented, screened for and/or detected early and treated at an early stage. ${ }^{6}$

This could significantly reduce the death rate from these cancers. ${ }^{7,8}$ Chennai and suburbs have a high incidence, of cervical cancer, ranking second, in India. ${ }^{4}$

Large population numbers and high rates of incidence of cancer cervix in low socioeconomic population groups in Chennai city and neighbouring districts poses a major problem for the health department. The government has recently introduced colposcopes to detect early precancerous lesions and early cancer of cervix. 
For the year 2012, the Chennai metropolitan cancer registry records showed that the relative proportion of cervical cancer for the area was reported as $12.6 \%$ and age adjusted incidence rate (for ages of 35 to 64 years) as 15.88 per lakh of population.

Screening for Prevention of Cancer of Cervix. ${ }^{9,10}$ The significant feature to note is, that the uterine cervix is accessible for inspection, the disease process is slow, and the precancerous stage is easily detected. One of the most effective ways of preventing, cervical cancer is regular screening and early detection of precancerous lesions of cervix and treatment of the same. Further Cervical cancer is preventable and curable if detected at an early stage. ${ }^{11,12}$

This study was conducted in a tertiary care Government Hospital for Women and Children, in Chennai, South India, which is a high incidence area for cervical cancer. More than $99 \%$ of attendees in the Colposcopy clinic, where cervical cancer screening is done, are from very low socioeconomic background. Women examined here constitute an adequate sample of the population from Chennai and neighbouring areas. These areas are high incidence regions for cervical cancer. Referees are from Out Patient Department, cervical cancer screening camps, Government centres, private hospitals. In patients from surgery, and gynaecology departments are also referred for cervical cancer screening including colposcopic examination prior to surgery, both gynaecological or general including organ donors and, the main referral centre for HIV positive women, for annual cervical cancer screening.

The study was to evaluate the efficacy of the various tests available in public health care centres in the state of Tamil Nadu, which are used for cervical cancer screening. The Objectives were to find out the efficacy of low-cost methods, available for screening for cervical cancer, in the health centres across the state for early detection of precancerous lesions, of cervix. Colposcopy clinic in a tertiary care public referral hospital, in Chennai. This study was conducted in a tertiary care Government Hospital for Women and Children, in Chennai, South India, which is a high incidence area for cervical cancer. More than $99 \%$ of attendees in the Colposcopy clinic, where cervical cancer screening is done, are from very low socioeconomic background. Women examined here constitute an adequate sample of the population from Chennai and neighbouring areas. These areas are high incidence regions for cervical cancer. Referees are from Out Patient Department, cervical cancer screening camps, Government centres, private hospitals. In patients from surgery, and gynaecology departments are also referred for cervical cancer screening including colposcopic examination prior to surgery, both gynaecological or general including organ donors and, the main referral centre for HIV positive women, for annual cervical cancer screening.

\section{METHODS}

Study Design: This study was conducted as a prospective, observational study. The sample size was calculated with formula, with power above $80 \%$, within a confidence interval limit of $95 \%$. This study was conducted over a period of thirty months.

Ethics Committee clearance: Prior to study commencement, approval to conduct this study was obtained from the Institutional Ethics Committee. Informed consent was obtained from all women participants in this study. Patient privacy was maintained.

Around 37,000 women attended OPD, in the Public Women and Children hospital, during the study period. A total of 960 women in all age groups were examined in the colposcopy clinic during this period.

\section{Inclusion criteria}

- Women aged below 50 years, attending colposcopy clinic for cervical cancer screening, with pap smear reports of ASCUS, LSIL or HSIL, or with previous diagnosis of CIN coming for follow up, were included.

\section{Exclusion criteria}

- Women aged above fifty years, pregnant and postpartum women up to six months after delivery, women diagnosed with cancer of cervix, those who had been previously treated for cancer of cervix, or who had undergone any surgery for uterine problems eg hysterectomy, trachellectomy, fothergill's surgery, were excluded.

Women were selected for inclusion in the study, after obtaining informed consent. A detailed history of participating women was noted. Reports of bimanual examination, and other tests such as ultrasonogram, if done, were recorded. Routine testing of pap smear followed by local examination was done for all women. HPV tests are not yet available in public hospitals as they are costly. As they have high sensitivity, HPV tests were done for a small group of $10 \%$ of the study participants, selected by random numbers. $(n=30)$.

Following pap smear, Visual inspection of cervix (VIA) after application of $5 \%$ Acetic acid, under low magnification of $6 x$, using colposcope was done. The results of the VIA tests were noted as positive or negative. Under higher magnification of $14 \mathrm{x}$, colposcopic findings were noted. The changes observed under colposcopy were noted. This was followed by Visual inspection of cervix after application of Lugol's iodine (VILI) under low magnification of 6x under colposcopic vision and followed by examination, under high magnification of $14 \mathrm{x}$. The colposcopic findings were 
noted. The VIA and VILI changes observed under magnification of $6 \mathrm{x}$, and colposcopic findings under magnification of $14 \mathrm{x}$ were recorded. We followed, Reid s modified colposcopic Index for scoring and colposcopic diagnosis. Biopsies from multiple sites of cervix were taken. To find out the efficacy of the various tests Papanicolaou smear, VIA, VILI and Colposcopy and HPV DNA tests, the results of the above-mentioned tests were compared with gold standard of histopathological examination reports of cervical biopsy tissue. All calculations were done using SPSS statistical software. The values for Sensitivity, Specificity, Positive Predictive Value, Negative Predictive Value of all the four tests of VIA, VILI, Pap smear and Colposcopy and HPV tests results were calculated to evaluate the efficacy of individual tests. The $\mathrm{p}$ values and Odds ratio, for all tests were compared. The women were divided into groups according to age namely women below 35 years, between 35 years and 50 years and the whole group of women aged below 50 years., and the tests results were calculated according to age group, and efficacy of test results compared in the three age groups.

\section{RESULTS}

A total number of 344 women were enrolled, in this study after obtaining informed consent. The enrolled women in the study were aged between twenty and fifty years. There were 100 women diagnosed with cervical intraepithelial neoplasia (CIN). The maximum numbers of women, who were diagnosed with CIN were aged between 35 to fifty years. These women formed $64 \%$ of the total group of women, diagnosed with CIN. A smaller number forming $36 \%$ of the group of women, diagnosed with CIN, were aged below 35 years (Figure 1).

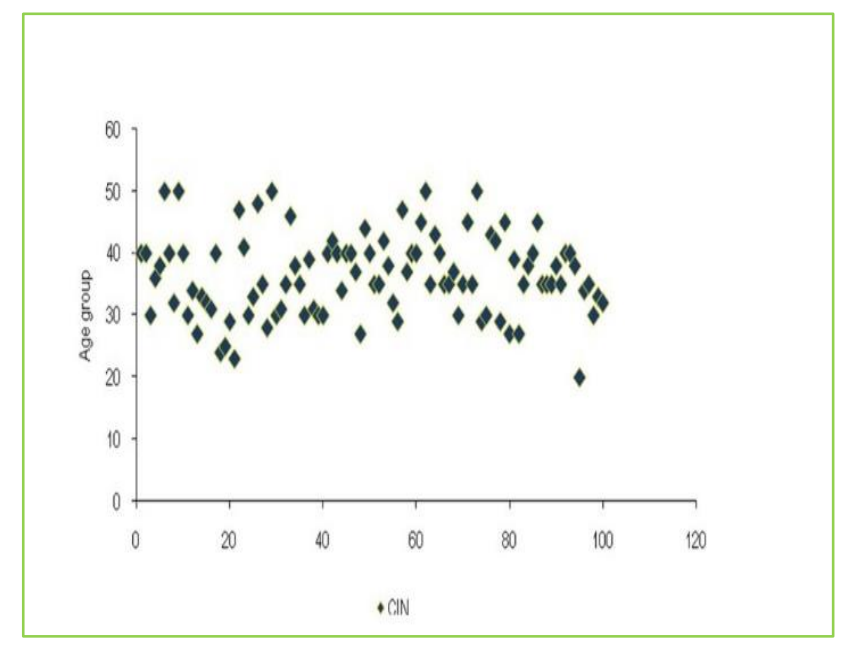

Figure 1: The scatter diagram shows maximum clustering in the age group between 30 and 40 years. There was significant correlation between parity and CIN, though $3 \%$ of women were nulliparous women and aged between twenty and thirty-five.
High grade lesions (HSIL) were detected in $19 \%$ of women and $74 \%$ of women with high grade lesions, CIN 2,3 were aged above 35 years, Low-grade lesions CIN 1 was detected in $81 \%$ of women and the majority of $62 \%$ of women in this group, were aged above 35 years. ${ }^{13,14}$ The age group 31 and 40 years had the maximum numbers of women with CIN, both high grade lesions CIN2, 3 and low grade lesions of CIN 1 (Figure 2). ${ }^{15-17}$

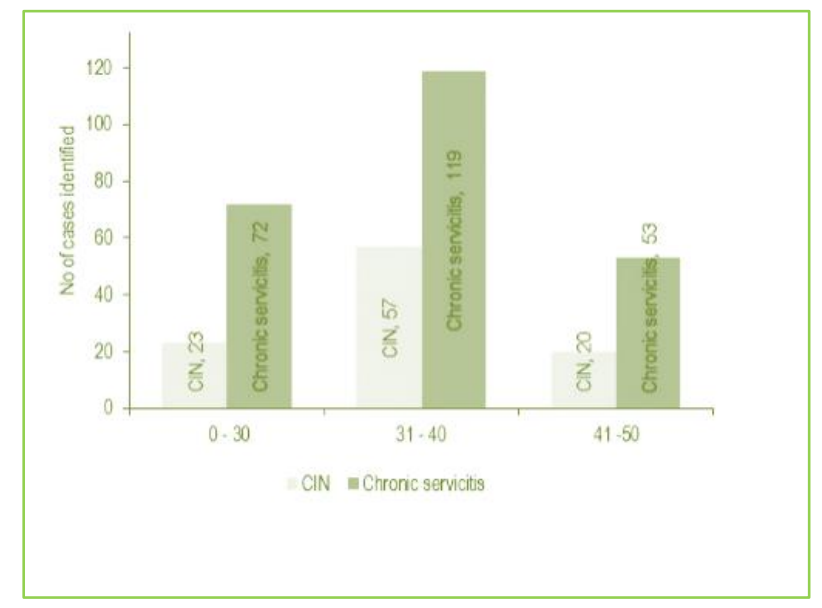

Figure 2: Identification of Women with CIN and women with chronic cervicitis, according to age groups. The diagram shows all three groups of women with CIN and women with chronic cervicitis.

The average age for the total group, of women diagnosed with CIN was 36.3 years $(n=100)$. The average age of women $(n=81)$ diagnosed with Low Grade lesions ( CIN1) was 36.5 years and that of women $(n=19)$, diagnosed with High Grade lesions (CIN2,3) was 35.4 years.

Table I shows the results for the screening tests of VIA and VILI under 6x magnification, Pap smear reports, colposcopic diagnosis for sensitivity, specificity, positive predictive values, negative predictive values and diagnostic accuracy, compared with the gold standard of histopathological reports of cervical biopsy. The $p$ value was significant for all the four tests of VIA, VILI both under 6x magnification, PAP smear and Colposcopy. To find out the efficacy of the basic tests described, for different age groups of women, we divided the group of women into three groups.

The first group, with women aged below 35 years, the second group with women aged between 35 years and 50 years, and the whole group of women aged 50 years and below.

Table 2 shows the results of tests compared for the three age groups. The identification of CIN among women is shown according to three age groups (Figure 2).

Low cost screening tests of VIA and VILI showed high specificity and diagnostic accuracy (Table 1 and 2) The 
diagnostic accuracy of colposcopy was highest at $86 \%$, (OR. 48.79) comparable in all age groups (Table 1,2 and Figure 3). A large number of $10 \%$ of the total group, were HIV positive women and $40 \%$ of them had CIN. The high specificity for VIA /VILI test of above 85 was effective even under low magnification of $6 x \cdot{ }^{18-20}$ Low cost tests of VIA and VILI would effectively help detect precancerous lesions, in a large group of women in all age groups. ${ }^{21,22}$

Table 1. Results of screening tests for all women.

\begin{tabular}{|llllll|}
\hline Tests & VIA & VILI & PAP & Colposcopy & HPV \\
\hline Sensitivity & 44 & 46 & 50 & 70 & 60 \\
\hline Specificity & 88 & 87 & 62 & 95 & 67 \\
\hline PPV & 81 & 78 & 55 & 90 & 64 \\
\hline NPV & 58 & 63 & 57 & 84 & 63 \\
\hline Diagnostic accuracy & 65 & 67 & 56 & 86 & 63 \\
\hline P value & 0.000001 & 0.000001 & 0.0002 & 0.000002 & 0.2 \\
\hline ODDS RATIO & 5.84 & 5.96 & 3.45 & 48.79 & 3 \\
\hline
\end{tabular}

The combination of low-cost tests of VIA and VILI were effective in detecting CIN in $75 \%$ of women and along with colposcopy in $93 \%$ of women. ${ }^{23,24}$

The diagnostic accuracy of Colposcopy, above 85, and Odds Ratio 48.79, was comparable in all age groups. ${ }^{25}$ Around $40 \%$ of the group of HIV positive women, attending colposcopy clinic were diagnosed with CIN, and HSIL was present in $30 \%$ of HIV positive women and LSIL in ten percent.

Table 2: Results of screening tests for all three age groups.

\begin{tabular}{|lcccc|}
\hline Tests & VIA & VILI & PAP & Colposcopy \\
\hline \multicolumn{2}{l}{ Diagnostic accuracy } & & & \\
\hline Age <35 years & 57 & 63 & 72 & 83 \\
\hline Age 35-50 years & 65 & 67 & 56 & 86 \\
\hline Age <50 years & 70 & 70 & 72 & 88 \\
\hline Specificity & & & & \\
\hline Age $<35$ years & 88 & 90 & 75 & 95 \\
\hline Age 35-50 years & 89 & 86 & 72 & 95 \\
\hline Age <50 years & 88 & 87 & 62 & 95 \\
\hline
\end{tabular}

The indication leucorrhoea was complained of by $55 \%$ of women with CIN and by more than $75 \%$ of women in the CIN negative group. It was significant to note that eight $\%$ of women with CIN were referred with utero-vaginal prolapse, for colposcopic evaluation, prior to surgery.

It may be mentioned here that, VIA was true negative for the majority of women with chronic cervicitis, and VIL was true negative for some, but false positive in only a few. Of the group of $19 \%$ of women with High grade lesions, CIN 2, 3, the majority of $63 \%,(n=12)$ had abnormal pap smears. The maximum numbers of women with CIN and HSIL were aged between 31 to 40 years. The average age of diagnosis of CIN was 36.3 years and for HSIL it was 35.4 years of age.

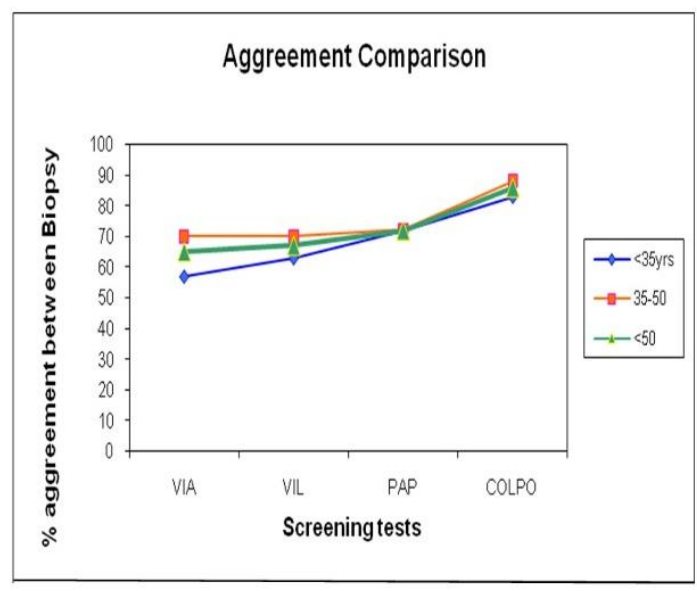

Figure 3: The agreement between results of diagnostic accuracy for VIA, VILI, PAP smears and colposcopy compared in all three groups is shown in the graph given below. It was found that overall as seen in combination the screening tests for all three groups of women were comparable. The specificity and diagnostic accuracy of VIA and VILI tests were highest in women in the age group of 35 to 50 years, though colposcopy was comparable in all three age groups.

\section{DISCUSSION}

With reference to the results obtained in the study, as a tool for prevention of cervical cancer we have arrived at an algorithm, for early detection of precancerous lesions of cervix among women, from a marginalized environment (Table 3). The low cost and available methods of VIA and VILI, Pap smear and colposcopy can be used, for screening women, for precancerous lesions of cervix. Screening should start five years after coitarche /marriage. Women with history of leading a life of risky behavior may be screened one to two years earlier. 


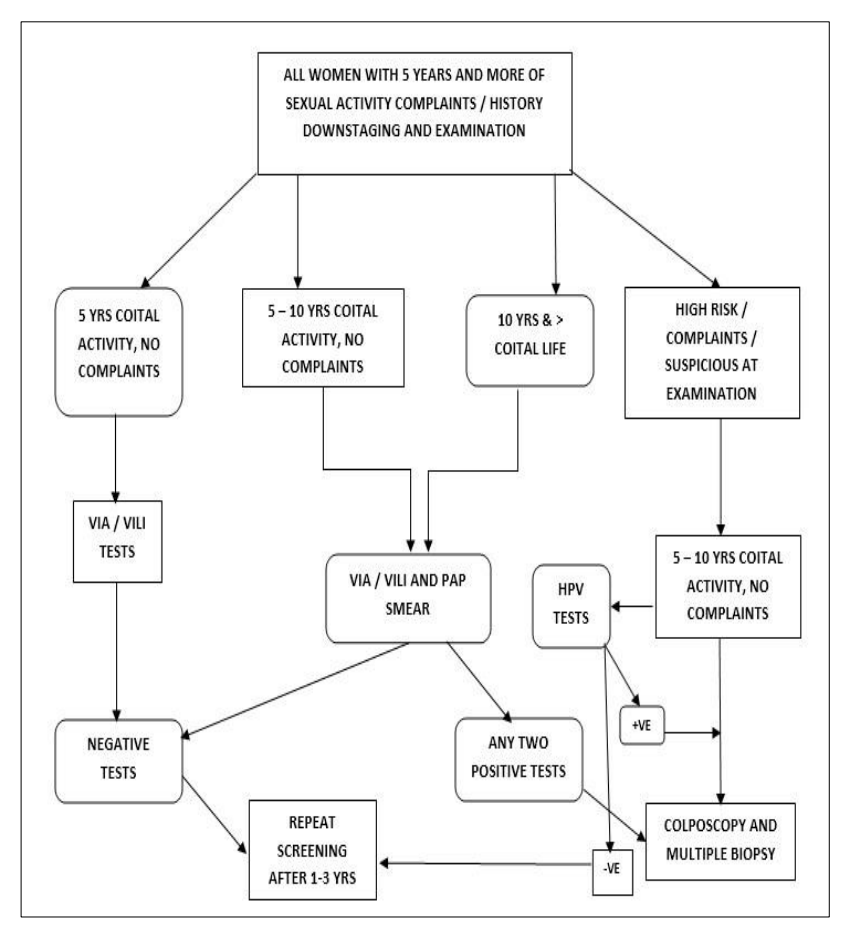

Figure 4: Revention of cervical cancer- an algorithm for early detection of precancerous lesions of cervix.

For women aged thirty and below with history of five to ten years of coital activity. The initial screening should be done with very low-cost tests of VIA and VILI under magnification. If any one test is positive, PAP smear should be taken. If any two tests are positive, woman should be referred for colposcopy. For women with negative test results, screening tests should be repeated after one year. For women aged above thirty and with history of more than ten years of coital activity, the tests of VIA, VILI under magnification and PAP smear should be taken. If any one test is positive, colposcopy should be done. Screening tests should be repeated after one year, for women with negative test results. If test results are negative for three consecutive years, repeat screening should be done after five years. Women can be advised to undergo screening test till the age of 60 years. Colposcopy should be done for women where at least two of the test results of VIA, VILI under magnification and Pap smear, are positive (Pap smear results of ASCUS and above). For all women in high risk group, such as HIV positive women and immune compromised women, those with previous diagnosis of CIN, and/or family history of cervical cancer and others, yearly colposcopy and where needed, colposcopic directed biopsy is recommended. HPV tests could be done wherever indicated, and for all high-risk cases, at cost effective selection. ${ }^{26-28}$ The algorithm arrived at could be adopted for early detection of precancerous lesions of cervix, and thereby prevention of cancer of cervix in women. Low cost screening tests of VIA and VILI showed high specificity and diagnostic accuracy. The high diagnostic accuracy rates of Colposcopy, above 85 , with Odds Ratio of 48.79 , was comparable in all age groups. The combination of low- cost tests of VIA and VILI were effective in detecting CIN in $75 \%$ of women and along with colposcopy in $93 \%$ of women. The simple and available methods could be used as explained for early detection of precancerous lesions of cervix, and thereby prevention of cancer of cervix in women from a marginalized environment.

\section{ACKNOWLEDGMENTS}

Authors would like to thank Dr. P. Venkatesan $\mathrm{PhD}$ (former Head), Dr. C. Ponnuraja PhD, Head, Statistics Department NIRT, Indian Council of Medical Research, for their support in statistical calculations.

\section{Funding: No funding sources \\ Conflict of interest: None declared}

Ethical approval: The study was approved by the Institutional Ethics Committee

\section{REFERENCES}

1. Bobdey S, Sathwara J, Jain A, Balasubramaniam G. Burden of cervical cancer and role of screening in India. Indian J Med Paediatr Oncol. 2016;37(4):27885.

2. Badwe RA, Dikshit R, Laversanne M, Bray F. Cancer incidence trends in India. Jap $\mathrm{J}$ Clinical Oncol. 2014;44(5):401-7.

3. Sreedevi A, Javed R, Dinesh A. Epidemiology of cervical cancer with special focus on India. Int $\mathrm{J}$ Women's Health. 2015;7:405.

4. India Against Cancer. Available at: cancer india.org.in/statistics/

5. Williams JH, Carter SM, Rychetnik L. 'Organised' cervical screening 45 years on: How consistent are organised screening practices? Europe J Cancer. 2014;50(17):3029-38.

6. Srinivasan S., Johari V., Jesani A. (2018) Cervical Cancer Screening in India. In: Schroeder D., Cook J., Hirsch F., Fenet S., Muthuswamy V. (eds) Ethics Dumping. SpringerBriefs in Research and Innovation Governance. Springer, Cham.

7. Human Papillomavirus and Related Cancers, Fact Sheet 2017. Available at: http://www.hpvcentre.net/statistics/reports/IND_FS.p df.

8. Jain S, Agarwal J, Bhaskar J, Cervical Cancer Prevention: Update 2017 for Indian Gynecologists.

9. Sankaranarayanan R, Esmy PO, Rajkumar R, Muwonge R, Swaminathan R, Shanthakumari S, et al. Effect of visual screening on cervical cancer incidence andmortality in Tamil Nadu, India: a cluster-randomised trial. The Lancet. 2007;370(9585):398-406.

10. Poli UR, Bidinger PD, Gowrishankar S. Visual Inspection with Acetic Acid (VIA) Screening Program: 7 Years' Experience in Early Detection of Cervical Cancer and Pre-Cancers in Rural South India. Indian J Community Med. 2015;40(3):203-7. 
11. Nandakumar A, Ramnath T, Chaturvedi M. The magnitude of cancer cervix in India. Indian $\mathbf{J}$ Med Res. 2009;130(3):219

12. Swaminathan R, Shanta V, Ferlay J, Balasubramanian S, Bray F, Sankaranarayanan R. Trends in cancer incidence in Chennai city (19822006) and statewide predictions of future burden in Tamil Nadu (2007-16). National Med J India. 2011;24(2):72.

13. Bhattacharyya AK, Nath JD, Deka H. Comparative study between pap smear and visual inspection with acetic acid (via) in screening of CIN and early cervical cancer. J Mid-life Health. 2015;6(2):53.

14. Dijkstra MG, van Zummeren M, Rozendaal L, van Kemenade FJ, Helmerhorst TJ, Snijders PJ, et al. Safety of extending screening intervals beyond five years in cervical screening programmes with testing for high risk human papillomavirus: 14-year followup of population based randomised cohort in the Netherlands. BMJ. 2016;355: i4924.

15. Castro B, Ribeiro DP, Oliveira J, Pereira MB, Sousa JC, Yaphe J. Cervical cancer screening: age limits, frequency and ideal examination: review of recent evidence and compared to the performance indicator evaluated in Portugal. Cien Saude Colet. 2014;19(4):1113-22.

16. Berenson AB, Hirth JM, Chang M. Change in human papillomavirus prevalence among US women aged 18-59 years, 2009-2014. Obstetrics and Gynecology. 2017;130(4):693-701.

17. Obel J, Souares Y, Hoy D, et al. A systematic review of cervical cancer incidence and mortality in the Pacific Region. Asian Pac J Cancer Prev. 2014;15(21):9433-7.

18. Sullivan R. Affordable cancer care: A Global Mirage? Available at: http://cancerworld.net/ourworld/affordable-cancer-care-a-global-mirage/.

19. Goodman A. HPV testing as a screen for cervical cancer. BMJ. 2015;350:h2372.

20. Hussain SA, Sullivan R. Cancer control in Bangladesh. Jap J Clin Oncol. 2013;43(12):1159-69.

21. Sawaya G, Smith-McCune K. Cervical Cancer Screening Obstet Gynecol. 2016;127(3):459-46.
22. Franceschi S, Wild CP. Meeting the global demands of epidemiologic transition - the indispensable role of cancer prevention. Mol Oncol. 2013;7(1):1-13.

23. Campos NG, Tsu V, Jeronimo J, Mvundura M, Lee $\mathrm{K}$, Kim JJ. When and how often to screen for cervical cancer in three low-and middle-income countries: a cost-effectiveness analysis. Papillomavirus Res. 2015;1:38-58.

24. Adamopoulou M, Kalkani E, Charvalos E, Avgoustidis D, Haidopoulos D, Yapijakis C. Comparison of cytology, colposcopy, HPV typing and biomarker analysis in cervical neoplasia. Anticancer Res. 2009;29(8):3401-9.

25. Raychaudhuri S, Mandal S. Current status of knowledge, attitude and practice(KAP) and screening for cervical cancer in countries at different levels of development. Asian Pac J Cancer Prev. 2012;13(9):4221-7.

26. Arbyn M, Fisher A, Martin-Hirsch PP, Zhao FH, Qiao Y. Low cost versus other screening tests to detect cervical cancer or precancer in developing countries. Cochrane Database of Systematic Reviews. 2012(11).

27. Hartwig S, Baldauf JJ, Dominiak-Felden G, Simondon F, Alemany L, de Sanjosé S, et al. Estimation of the epidemiological burden of HPVrelated anogenital cancers, precancerous lesions, and genital warts in women and men in Europe: Potential additional benefit of a nine-valent second-generation HPV vaccine compared to first generation HPV vaccines. Papillomavirus Research. 2015;01:90-100.

28. Bosch FX, Broker TR, Forman D. Comprehensive Control of HPV Infections and Related Diseases. Monograph Vaccine. 2012;30(5).

Cite this article as: Christe DM, Chandrasekar A, Jayashree K, Meenalochani P, Gunasingh STK. Prevention of cervical cancer: early detection of precancerous lesions of cervix in women from a marginalized environment. Int J Reprod Contracept Obstet Gynecol 2018;7:5156-61. 